\title{
Reproductive factors and the risk of triple- negative breast cancer in white women and African-American women: a pooled analysis
}

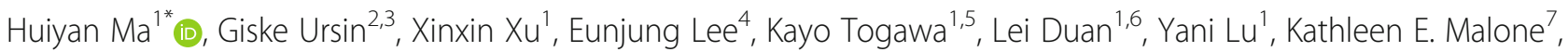
Polly A. Marchbanks ${ }^{8}$, Jill A. McDonald ${ }^{9}$, Michael S. Simon ${ }^{10}$, Suzanne G. Folger ${ }^{8}$, Jane Sullivan-Halley ${ }^{1}$,

Dennis M. Deapen ${ }^{4}$, Michael F. Press ${ }^{11}$ and Leslie Bernstein ${ }^{1}$

\begin{abstract}
Background: Early age at menarche, nulliparity, late age at first completed pregnancy, and never having breastfed, are established breast cancer risk factors. However, among breast cancer subtypes, it remains unclear whether all of these are risk factors for triple-negative breast cancer (TNBC).

Methods: We evaluated the associations of these reproductive factors with TNBC, in 2658 patients with breast cancer (including 554 with TNBC) and 2448 controls aged 20-64 years, who participated in one of the three population-based case-control studies: the Women's Contraceptive and Reproductive Experiences Study, the Women's Breast Carcinoma in situ Study, or the Women's Learning the Influence of Family and Environment Study. We used multivariable polychotomous unconditional logistic regression methods to conduct case-control comparisons among breast cancer subtypes defined by estrogen receptor, progesterone receptor, and human epidermal growth factor receptor-2 expression status.

Results: TNBC risk decreased with increasing duration of breastfeeding $\left(P_{\text {trend }}=0.006\right)$, but age at menarche, age at first completed pregnancy, and nulliparity were not associated with risk of TNBC. Parous women who breastfed for at least one year had a $31 \%$ lower risk of TNBC than parous women who had never breastfed (odds ratio, $O R=0.69$; 95\% confidence interval, $\mathrm{Cl}=0.50-0.96)$. The association between breastfeeding and risk of TNBC was modified by age and race. Parous African-American women aged 20-44 years who breastfed for 6 months or longer had an 82\% lower risk of TNBC than their counterparts who had never breastfed ( $\mathrm{OR}=0.18,95 \% \mathrm{Cl}=0.07-0.46)$.
\end{abstract}

Conclusions: Our data indicate that breastfeeding decreases the risk of TNBC, especially for younger African-American women.

Keywords: Reproductive factors, Breastfeeding, Triple-negative breast cancer, Luminal A, White women, AfricanAmerican women

\footnotetext{
* Correspondence: hma@coh.org

${ }^{1}$ Department of Population Sciences, Beckman Research Institute, 1500 East

Duarte Rd. Duarte, City of Hope, CA 91010, USA

Full list of author information is available at the end of the article
} 


\section{Background}

Breast cancer occurs more frequently than any other type of cancer in women worldwide, with an estimated 1.4 million new cases annually [1]. Based on immunohistochemical analyses of estrogen receptor (ER), progesterone receptor (PR), and human epidermal growth factor receptor-2 (HER2), breast cancer has been classified into luminal A-like (ER-positive $(\mathrm{ER}+)$ and/or PR-positive $(\mathrm{PR}+)$, HER2-negative (HER2-)), luminal B-like (ER+ and/or PR+, HER2-positive (HER2+)), HER2-enriched (ER-negative (ER-)/PR-negative (PR-)/HER2+), and triplenegative breast cancer (TNBC; ER-/PR-/HER2-) [2-10].

The luminal A-like subtype is the most frequent subtype and accounts for $62-67 \%$ of invasive cases; TNBC is the second most common subtype and accounts for $10-25 \%$ of invasive cases $[11,12]$. Compared with the luminal A-like subtype, TNBC is disproportionately more common in younger or premenopausal women, especially young African-American women [13-16]. TNBC is biologically more aggressive and has poorer prognosis than the luminal A-like subtype [7, 12, 17]. Moreover, unlike ER+ or HER2+ breast cancer, for which there are targeted therapies, including antiestrogen and monocolonal antibody therapies, there are no targeted therapies for TNBC $[12,18]$. Therefore, currently the only treatment option for TNBC is systemic chemotherapy $[12,18]$. The overall 5-year survival rate in patients with TNBC is at least $10 \%$ lower than in women with the luminal A-like subtype [19]. These TNBC characteristics underscore the need to identify specific TNBC risk factors, which could provide critical clues for TNBC prevention strategies. However, the impact of established breast cancer risk factors, such as reproductive factors, on the risk of TNBC remains inconclusive, possibly because too few patients with TNBC have been included in the majority of published studies $[6,10,15$, 20-32]. Moreover, little is known about the impact of race and age on reproductive risk of TNBC.

Here, we evaluated the associations between TNBC and age at menarche, number of completed (longer than 26-week gestation) pregnancies, age at first completed pregnancy, and breastfeeding in an analysis pooling data from three case-control studies. We compared the risk estimates for TNBC with other ER/PR/HER2-defined specific subtypes, especially luminal A-like breast cancer. We also explored whether the associations between these factors and risk of TNBC differ by race (white, African-American) and age ( $<45, \geq 45$ years). Among our three source studies, one has published data on reproductive factors (including number of completed pregnancies, age at first completed pregnancy, and breastfeeding) and the risk of breast cancer by ER/PR/HER2 status [6]. Another has published data on hormone-related risk factors for breast cancer by ER/PR status [33] and has also published characteristics of TNBC in patients with and without a BRCA1 mutation [34]. No data on breast cancer risk according to the expression of ER, PR, or HER2 have been published from the third study [35].

\section{Methods}

\section{Study population and data collection}

Eligible participants for this analysis were women who had previously participated in one of the three populationbased case-control studies - the Women's Contraceptive and Reproductive Experiences (CARE) Study [6], the Women's Breast Carcinoma in situ (BCIS) Study [35], or the Women's Learning the Influence of Family and Environment (LIFE) Study [33].

The Women's CARE Study, which was supported by National Institute of Child Health and Human Development (NICHD), was a population-based, case-control study designed to examine risk factors for invasive breast cancer among USA-born white women and AfricanAmerican women [36]. The age distribution and participant response rates by study site, case-control status, and race have been published [36]. The Women's CARE Study selected a stratified (by age group) random sample of women aged 35-64 years who were newly diagnosed with histologically confirmed incident invasive breast cancer (International Classification of Diseases for Oncology (ICD-O) codes: C50.0-C50.9) between July 1994 and April 1998. African-American women were oversampled to maximize their numbers in the study, and white women were sampled to provide approximately equal numbers of women in each 5-year age category (from 35 to 64 years).

Control participants were women with no history of invasive or in situ breast cancer who were identified by random digit dialing from August 1994 through December 1998 and were frequency-matched to the expected distribution of patients with breast cancer in strata defined by 5 -year age groups, race (white or African-American) and geographic region of residence [6]. The participants in the Women's CARE Study involved in the analyses presented here are women from Los Angeles (LA) and Detroit, the two sites where tumor tissue samples were collected. Tissue collection, as part of the Women's CARE Study, was supported by NICHD, as advised by the Women's CARE Study Steering Committee [36]. The Women's CARE Study recruited 1921 case participants (1072 white and 849 African-American women) and 2034 control participants (1161 white and 873 AfricanAmerican women) from LA and Detroit. Of 1921 case participants, 1206 had ER/PR/HER2 status assessed in a centralized pathology laboratory at University of Southern California (USC).

The Women's BCIS Study investigated risk factors for BCIS among USA-born white women and African- 
American women who resided in LA County [35]. Case participants were USA-born and English-speaking white women and African-American women ages 35-64 years, who were newly diagnosed with a first primary BCIS (ICD-O codes: C50.0-C50.9) between March 1995 and April $1998(n=567)$. The questionnaire developed for the Women's CARE Study was used to interview women with BCIS, and both studies were conducted during the same time period by the same interviewers and with ER, PR and HER2 status determined in the same central laboratory using the same classifications (see subsequent text). No additional controls were recruited for the BCIS Study. LA control participants from the Women's CARE Study were deemed eligible to be controls for the BCIS Study. For the analysis presented here, we excluded 37 case participants with lobular carcinoma in situ (LCIS, ICD-O morphology code: 8520 ) because LCIS is not included in the clinical definitions of in situ breast cancer [37]; thus, 530 case participants remained. ER/PR/HER2 status was assessed in 343 of these case participants, at a centralized pathology laboratory at USC.

The Women's LIFE Study investigated genetic and epidemiologic risk factors for invasive breast cancer in USA-born white women and African-American women who resided in LA County [33, 38]. Case participants were women aged 20-49 years who were diagnosed with a first primary invasive breast cancer (ICD-O codes: C50.0-C50.9) between February 1998 and May 2003 and who resided in LA county $(n=1794)$. Of 1794 case participants, 1167 had ER/PR/HER2 status abstracted from pathology reports. Control participants were women ages 20-49 years who had no history of invasive or in situ breast cancer. Recruitment of control participants did not begin until 1 July 2000. Control participants were individually matched by race (white and AfricanAmerican), age (within 5 years and ages 20-49 years), and neighborhood to the subset of case participants who were diagnosed between 1 July 2000 and 31 May 2003 $(n=444)$. The Women's LIFE Study used an expanded version of the Women's CARE Study questionnaire, which was modified to include additional risk factors (e.g., medical radiation exposure).

For all three studies, detailed information prior to the reference date on reproductive factors and covariates involved in this analysis was collected by trained staff who administered standardized, in-person interviews using structured questionnaires. The reference date for a case participant was the date of breast cancer diagnosis; the reference date for a control participant was the date on which she was identified by random digit dialing in the Women's CARE Study, or the date of initial contact in the Women's LIFE Study.

After pooling the data from three source studies, 2716 case participants with data on receptors and 2478 control participants were potentially eligible. We excluded 58 case participants and 30 control participants for whom information was missing on age at menarche (4 cases, 1 control), parity (4 cases, 6 controls), duration of oral contraceptive use (16 cases, 5 controls), education ( 9 cases, 1 control), body mass index (BMI, 15 cases, 12 controls), recreational physical activity (5 cases, 3 controls), smoking status (2 cases), and alcohol intake (3 cases, 2 controls). This resulted in 2658 case participants (the Women's CARE Study: 1197, the Women's BCIS Study: 342, the Women's LIFE Study: 1119 ) and 2448 control participants (the Women's CARE Study or the Women's BCIS Study: 2011, the Women's LIFE Study: 437) available for the current pooled analysis.

\section{Assessment of biomarkers}

The ER/PR/HER2 status in breast tumors in the Women's CARE Study and the Women's BCIS Study was determined in a centralized pathology laboratory at USC using immunohistochemistry (IHC) methods [39, 40]. For ER and PR, at least 100 tumor cells were examined from each specimen and immunostaining of tumor cell nuclei $\geq 1 \%$ was considered positive [41]. HER2 expression was determined by $\mathrm{IHC}$ using the $10 \mathrm{H} 8$ monoclonal antibody $[42,43]$. No (0) or weak $(1+)$ membrane immunostaining was considered HER2-. Moderate (2+) or strong membrane immunostaining (3+) was considered HER2+, based on previous validation results from the same pathology laboratory [42]. In the Women's LIFE Study, the information on ER/PR/HER2 status was abstracted from pathology reports collected through the Los Angeles Cancer Surveillance Program (LACSP), a member of the population-based California Cancer Registry and also sponsored by the National Cancer Institute's SEER program [34].

The ER/PR/HER2 status abstracted from pathology reports for case participants in the Women's LIFE Study was assessed by many pathology laboratories. These laboratories might have used different methods or different cut-off points for positive receptor status, which could cause concerns about consistency with the biomarker data from the centralized pathology laboratory at USC. We previously validated the SEER registry ER/PR status data for 1048 Women's CARE case participants in the centralized pathology laboratory at USC, which showed that the agreement between the centralized laboratory and SEER registry classification was substantial for both ER/PR ( $\kappa$ statistics: 0.70 and 0.60 for ER and $\mathrm{PR}$, respectively), and that the associations between risk of ER/PR breast cancer subtypes and parity, age at first completed pregnancy, and breastfeeding were similar regardless of the source of information on ER/PR [44].

\section{Statistical analyses}

We assessed the associations between TNBC (ER-/PR-/ HER2-) or the other three subtypes of breast cancer 
defined by ER/PR/HER2 status (luminal A-like, ER+ and/or PR+ plus HER2-; luminal B-like, ER+ and/or PR+ plus HER2+; and HER2-enriched, ER-/PR-/HER2+), and the following factors: age at menarche, number of completed (longer than 26-week gestation) pregnancies, age at first completed pregnancy (defined for each woman as the age at which that pregnancy ended), and duration of breastfeeding. We estimated odd ratios (ORs) and corresponding 95\% confidence intervals (95\% CIs) using multivariable polychotomous unconditional logistic regression for case-control comparisons [45].

Tests for trend were conducted by fitting ordinal values corresponding to exposure categories and testing whether the slope coefficient differed from zero. We also conducted Wald chi-square tests for homogeneity of the associations with reproductive factors across breast cancer subtypes by fitting a multivariable polychotomous unconditional logistic regression model for dichotomous or ordinal variables.

We included the following factors, selected a priori, as potential confounders in all multivariable models: source study (the Women's CARE Study or the Women's BCIS Study, the Women's LIFE Study), study site (LA, Detroit), race (white, African-American), education as a proxy for socioeconomic status (high school or lower level of education, technical school or some college education, college graduate), age (<40, 40-44, 45-49, 50-54, 55-59, 60-64 years), family history of breast cancer (first-degree (mother, sister, or daughter), no first-degree family history), BMI $\left(<25,25-29, \geq 30 \mathrm{~kg} / \mathrm{m}^{2}\right)$, a variable combining menopausal status and hormone therapy use (premenopausal; postmenopausal: never used hormone therapy, ever used hormone therapy; unknown menopausal status), lifetime recreational physical activity (inactive, $\leq 2.2,2.3-$ $6.6,6.7-15.1, \geq 15.2$ annual metabolic equivalents of energy expenditure (MET) hours/week), alcohol intake (never, former, current), cigarette smoking status (never, former, current), and oral contraceptive use (never, $<1,1-4,5-9, \geq 10$ years).

We also included age at menarche $(\leq 12,13, \geq 14)$ and number of completed pregnancies (never pregnant, $1,2, \geq 3$, only non-completed pregnancy) as potential confounders when they were not the exposure of interest. When parity was the exposure of interest, we chose women who had never been pregnant as our reference group and treated women who had been pregnant but had never carried to completed pregnancy as a separate group that was excluded when testing for trend across categories of parity. Only parous women were included in analyses of age at first completed pregnancy and breastfeeding. Models for parous women were also mutually adjusted for number of completed pregnancies $(1,2, \geq 3)$, age at first completed pregnancy $(\leq 20,21-24,25-29, \geq 30$ years), and duration of breastfeeding (never, $<6,6-11, \geq 12$ months).
Using two major subtypes - TNBC and luminal A-like breast cancer, we explored whether any associations of reproductive factors differed by race (white women or African-American women) or age group (younger ( $<45$ years) or older ( $\geq 45$ years) women). In stratified analyses by age, the variable for combining menopausal status and hormone therapy use was only included in the models for older women. When testing the effect of breastfeeding by both race and age, we combined two categories (6-11, $\geq 12$ months) of longer duration of breastfeeding into one ( $\geq 6$ months) to avoid having groups with small numbers of study participants after stratification.

As the commonly used definition (ER+ and/or PR+ plus HER2-) of the luminal A-like subtype probably includes both luminal B-like and luminal A-like tumors, we also used the $13^{\text {th }}$ St. Gallen International Breast Cancer Conference (2013) Expert Panel recommendation to define ER+/PR+/HER2- as the luminal A-like subtype [46], and repeated our analysis by the following five subtypes: luminal A-like (ER+/PR+/HER2-), luminal B-like-HER2- (ER+ or PR+ plus HER2-), luminal B-likeHER2+ (ER+ and/or PR+ plus HER2+), HER2-enriched (ER-/PR-/HER2+), and TNBC (ER-/PR-/HER2-). It is noteworthy that the St. Gallen Panel recommendation requires information on Ki-67 and percentage of PR in PR+ tumors; however, we lacked data on Ki-67 in all source studies and did not have quantitative data for PR in the Women's LIFE Study. Moreover, in order to exclude the possibility that ORs for some reproductive factors associated with in situ breast cancer are different from those associated with the results presented here, we repeated our analyses after excluding all in situ breast cancer cases.

In reporting the results of trend tests or homogeneity tests, we considered a two-sided $P$ value $<0.05$ as statistically significant. All analyses were performed using the SAS statistical package (Version 9.3, SAS Institute, Cary, NC, USA).

\section{Results}

\section{Characteristics of case participants and controls}

The subtypes of breast cancer in the 2658 case participants were distributed as: TNBC $(n=554,20.8 \%)$, luminal A-like $(n=1517,57.1 \%)$, luminal B-like $(n=360$, $13.5 \%)$, and HER2-enriched $(n=227,8.5 \%)$ (Table 1). The 2448 control participants comprised 1549 white women and 899 African-American women. Overall, mean age at menarche in control participants was 12.4 years; $81.3 \%$ of control participants had at least one completed pregnancy. Among control participants, the mean number of completed pregnancies was 2.7 in parous women, and their mean age at first completed pregnancy was 23.2 years. Among parous control participants who had ever breastfed (62.4\%), the mean duration of breastfeeding was 12.1 months. 
Table 1 Characteristics of breast cancer case participants and control participants

\begin{tabular}{|c|c|c|c|c|}
\hline & \multirow[t]{2}{*}{ Overall } & \multicolumn{3}{|l|}{ By study } \\
\hline & & Women's CARE & Women's BCIS & Women's LIFE \\
\hline Case participants & $N=2658$ & $N=1197$ & $N=342$ & $N=1119$ \\
\hline Mean age at diagnosis, years (SD, range) & $46.7(8.1,22-64)$ & $49.0(8.6,35-64)$ & $51.8(7.3,35-64)$ & $42.7(5.4,22-49)$ \\
\hline \multicolumn{5}{|l|}{ Race } \\
\hline White & $1960(73.7 \%)$ & $678(56.6 \%)$ & $287(83.9 \%)$ & $995(88.9 \%)$ \\
\hline African-American & $698(26.3 \%)$ & $519(43.4 \%)$ & $55(16.1 \%)$ & $124(11.1 \%)$ \\
\hline \multicolumn{5}{|l|}{ Subtype of breast cancer } \\
\hline Triple-negative & $554(20.8 \%)$ & $335(28.0 \%)$ & $21(6.1 \%)$ & $198(17.7 \%)$ \\
\hline Luminal A-like & $1517(57.1 \%)$ & $645(53.9 \%)$ & $233(68.1 \%)$ & $639(57.1 \%)$ \\
\hline Luminal B-like & $360(13.5 \%)$ & $121(10.1 \%)$ & 49 (14.3\%) & $190(17.0 \%)$ \\
\hline HER2-enriched & $227(8.5 \%)$ & $96(8.0 \%)$ & 39 (11.4\%) & $92(8.2 \%)$ \\
\hline Control participants & $N=2448$ & $N=2011^{a}$ & - & $N=437$ \\
\hline Mean age at reference date, years (SD, range) & $47.8(8.3,24-64)$ & $48.9(8.4,35-64)$ & - & $42.6(4.9,24-49)$ \\
\hline \multicolumn{5}{|l|}{ Race } \\
\hline White & $1549(63.3 \%)$ & $1147(57.0 \%)$ & - & $402(92.0 \%)$ \\
\hline African-American & $899(36.7 \%)$ & $864(43.0 \%)$ & - & $35(8.0 \%)$ \\
\hline Mean age at menarche, years (SD) & $12.4(1.6)$ & $12.4(1.6)$ & - & $12.7(1.5)$ \\
\hline Ever had a completed (>26-week) pregnancy & $1990(81.3 \%)$ & $1677(83.4 \%)$ & - & $313(71.6 \%)$ \\
\hline Among parous women & $N=1990$ & $N=1677$ & & $N=313$ \\
\hline Mean number of completed pregnancies (SD) & $2.7(1.5)$ & $2.8(1.6)$ & - & $2.2(1.1)$ \\
\hline Mean age at first completed pregnancy (SD) & $23.2(5.7)$ & $22.5(5.3)$ & - & $27.1(6.2)$ \\
\hline Ever breastfed & $1242(62.4 \%)$ & $967(57.7 \%)$ & - & $275(87.9 \%)$ \\
\hline Mean duration of breastfeeding among those who breastfed, months (SD) & $12.1(15.0)$ & $10.9(14.4)$ & - & $16.2(16.5)$ \\
\hline
\end{tabular}

Including those who also served as controls in the Women's BCIS. Triple-negative = estrogen receptor (ER)-/progesterone receptor (PR)-/human epidermal growth factor receptor-2 (HER2)-, Luminal A-like $=$ ER+ and/or PR+ plus HER2-, Luminal B-like $=$ ER+ and/or PR+ plus HER2+, HER2-enriched $=$ ER-/ PR-/HER2+. CARE Contraceptive and Reproductive Experiences Study, BCIS Breast Carcinoma in situ Study, LIFE Learning the Influence of Family and Environment Study

\section{Reproductive factors and risk of four ER/PR/HER2-defined subtypes}

Age at menarche was not associated with TNBC $\left(P_{\text {trend }}=0.55\right.$; Table 2$)$, luminal B-like $\left(P_{\text {trend }}=0.70\right)$, or HER2-enriched $\left(P_{\text {trend }}=0.56\right)$ breast cancer, but was associated with luminal A-like subtype $\left(P_{\text {trend }}=0.009\right)$. Women whose menarche occurred at age 14 years or later had a $23 \%$ lower risk of luminal A-like breast cancer (OR $=0.77,95 \% \mathrm{CI}=0.64-0.92)$ than women whose menarche occurred at age 12 years or earlier. Number of completed pregnancies was not associated with the risk of TNBC $\left(P_{\text {trend }}=0.26\right)$, but was inversely associated with the risk of the other three subtypes (all $P_{\text {trend }} \leq 0.02$ ).

Among parous women, older age at first completed pregnancy was not associated with any ER/PR/HER2-defined specific subtypes, except for the luminal A-like subtype $\left(P_{\text {trend }}=0.05\right)$. There was a statistically significant inverse association between longer duration of breastfeeding and TNBC $\left(P_{\text {trend }}=0.006\right)$ and luminal Alike cancer $\left(P_{\text {trend }}=0.004\right)$, but no association with the other two subtypes of breast cancer (both $P_{\text {trend }} \geq 0.28$ ).
None of the differences in trends across the four subtypes of breast cancer was statistically significant for age at menarche $(P$ for homogeneity of trends $=0.19)$, parity $(P$ for homogeneity of trends $=0.09$ ), age at first completed pregnancy $(P$ for homogeneity of trends $=0.24)$, or duration of breastfeeding ( $P$ for homogeneity of trends $=0.08$ ).

\section{Reproductive factors and risk of TNBC and luminal A-like subtype by race}

Among either white women or African-American women, risk of TNBC was not associated with age at menarche number of completed pregnancies, or age at first completed pregnancy (Table 3). However, among white women, risk of luminal A-like breast cancer was inversely associated with age at menarche $\left(P_{\text {trend }}=0.02\right)$ and number of completed pregnancies $\left(P_{\text {trend }}=0.0005\right)$.

Longer duration of breastfeeding was modestly associated with a lower risk of TNBC in parous AfricanAmerican women and a lower risk of the luminal A-like subtype in both parous white women and parous AfricanAmerican women; however, statistically significant dose- 
Table 2 Multivariable adjusted odds ratio (OR) and 95\% confidence interval (Cl) for ER/PR/HER2-defined subtypes of breast cancer associated with reproductive factors

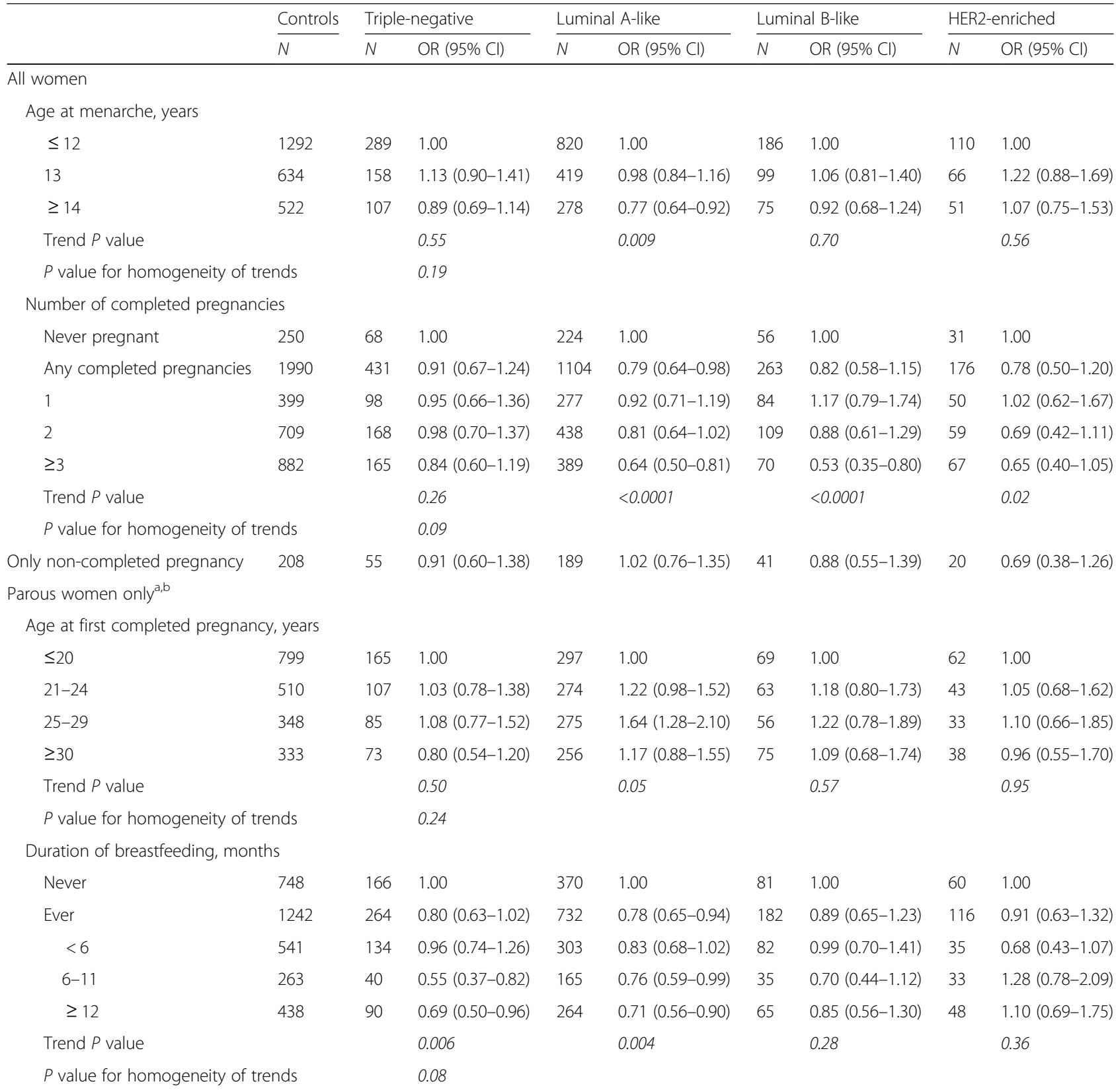

Models in multivariate analysis included sub-study (the Women's CARE Study or the Women's BCIS Study, the Women's LIFE Study), study site (Los Angeles, Detroit), race (white, African-American), reference age (in 5-year age categories), education ( $\leq$ high school, technical school or some college, college graduate), first-degree breast cancer family history (no, yes), body mass index $\left(<25,25-29, \geq 30 \mathrm{~kg} / \mathrm{m}^{2}\right)$, a variable combining menopausal status and hormone therapy use (premenopausal; postmenopausal: never used hormone therapy, ever used hormone therapy; unknown menopausal status), lifetime recreational physical activity (inactive, $\leq 2.2,2.3-6.6,6.7-15.1, \geq 15.2$ annual metabolic equivalents of energy expenditure, hour/week), alcohol intake (never, former, current), cigarette smoking status (never, former, current), age at menarche $(\leq 12,13, \geq 14$ years), number of completed pregnancies (never pregnant, 1,2 , $\geq 3$, only non-completed pregnancy), oral contraceptive use (never, $<1,1-4,5-9, \geq 10$ years). ${ }^{a}$ Models additionally included age at first completed pregnancy $(\leq 20,21-24,25-29, \geq 30$ years) and duration of breastfeeding (never, $<6,6-11, \geq 12$ months). ${ }^{b}$ Additionally seven parous case participants who had missing information on breastfeeding were excluded. Triple negative $=$ estrogen receptor $(\mathrm{ER})-$ /progesterone receptor $(\mathrm{PR})-$ /human epidermal growth factor receptor-2 (HER2)-, Luminal A-like $=\mathrm{ER}+$ and/or PR+ plus HER2-, Luminal B-like = ER+ and/or PR+ plus HER2+, HER2-enriched = ER-/PR- /HER2 +

response relationships were only observed in TNBC $\left(P_{\text {trend }}=0.01\right)$ and the luminal A-like subtype $\left(P_{\text {trend }}=0.04\right)$ among the African-American women. Among parous African-American women, breastfeeding for 12 months or longer compared to never breastfeeding was associated with a $45 \%$ lower risk of TNBC $(\mathrm{OR}=0.55,95 \% \mathrm{CI}=0.32$ 0.94 ), and $43 \%$ lower risk of luminal A-like breast cancer $(\mathrm{OR}=0.57,95 \% \mathrm{CI}=0.36-0.90)$. 
Table 3 Multivariable adjusted odds ratio (OR) and 95\% confidence interval (Cl) for ER/PR/HER2-defined subtypes of breast cancer associated with reproductive factors by race

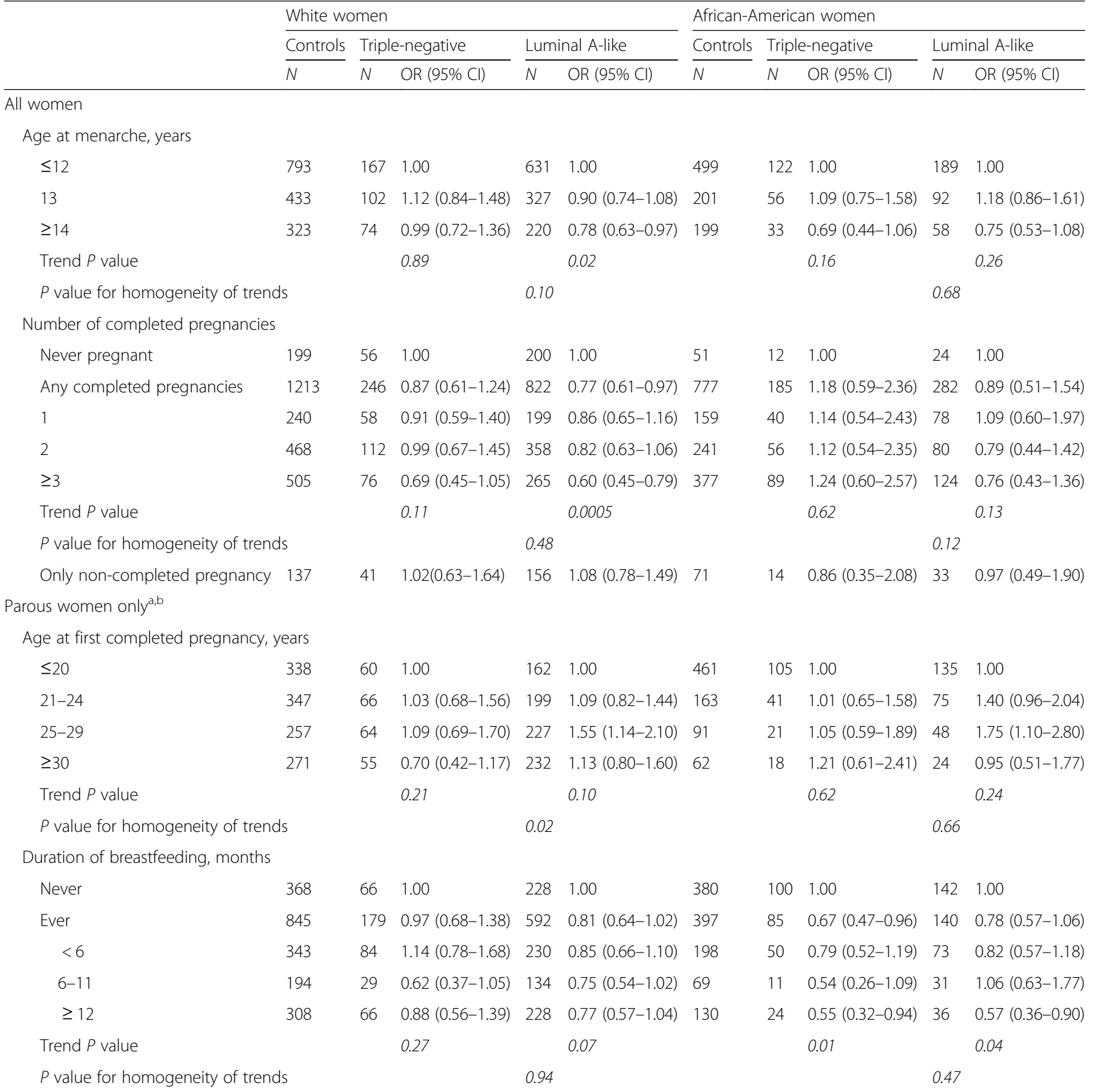

Triple negative $=$ estrogen receptor (ER)-/progesterone receptor (PR)-/human epidermal growth factor receptor-2 (HER2)-, Luminal A-like $=E R+$ and/or PR+ plus HER2. Models in multivariate analysis included sub-study (the Women's CARE Study or the Women's BCIS Study, the Women's LIFE Study), study site (Los Angeles, Detroit), reference age (in 5-year age categories), education ( $\leq$ high school, technical school or some college, college graduate), first-degree breast cancer family history (no, yes), body mass index $\left(<25,25-29, \geq 30 \mathrm{~kg} / \mathrm{m}^{2}\right)$, a variable combining menopausal status and hormone therapy use (premenopausal; postmenopausal: never used hormone therapy, ever used hormone therapy; unknown menopausal status), lifetime recreational physical activity (inactive, $\leq 2.2,2.3-6.6,6.7-15.1, \geq 15.2$ annual metabolic equivalents of energy expenditure, hour/week), alcohol intake (never, former, current), cigarette smoking status (never, former, current), age at menarche $(\leq 12,13, \geq 14$ years), number of completed pregnancies (never pregnant, $1,2, \geq 3$, only non-completed pregnancy), oral contraceptive use (never, $<1,1-4$, $5-9, \geq 10$ years). ${ }^{a}$ Models additionally included age at first completed pregnancy $(\leq 20,21-24,25-29, \geq 30$ years) and duration of breastfeeding (never, $<6,6-11, \geq 12$ months). ${ }^{\mathrm{b}}$ Additionally, three white parous cases who had missing information on breastfeeding were excluded

The difference in trends across TNBC and luminal Alike breast cancer was only statistically significant for age at first completed pregnancy among parous white women $(P$ for homogeneity of trends $=0.02)$; none of the other factors differed significantly between these two subtypes ( $P$ for homogeneity of trends $\geq 0.10$ ). 


\section{Reproductive factors and risk of TNBC and the luminal A-like subtype by age}

Similar to the results for all age groups combined, early age at menarche, nulliparity, and older age at first completed pregnancy were not associated with risk of TNBC in either younger or older women $\left(P_{\text {trend }} \geq 0.13\right.$, Table 4$)$. However, younger women (aged 20-44 years) whose menarche occurred at age 14 years or later had a $37 \%$ lower risk of luminal A-like breast cancer $(\mathrm{OR}=0.63,95 \% \mathrm{CI}$ $=0.47-0.85)$ than those whose menarche occurred at age 12 years or earlier $\left(P_{\text {trend }}=0.004\right)$. Number of completed pregnancies was inversely associated with the risk of luminal A-like subtype cancer among both younger $\left(P_{\text {trend }}=0.02\right)$ and older women $\left(P_{\text {trend }}=0.006\right)$. Among older parous women, age at first completed pregnancy was positively associated with the risk of the luminal Alike subtype $\left(P_{\text {trend }}=0.01\right)$; those who had their first completed pregnancies at or after age 30 years had a higher risk of the luminal A-like subtype than those who had their first completed pregnancies at or prior to age 20 years $(\mathrm{OR}=1.32,95 \% \mathrm{CI}=0.91-1.90)$. Duration of breastfeeding was inversely associated with the risk of both TNBC and luminal A-like breast cancer subtypes in both younger and older parous women.

The differences in trends across TNBC and luminal Alike breast cancer were statistically significant only for the number of completed pregnancies among younger women ( $P$ for homogeneity of trends $=0.03$ ).

\section{Breastfeeding and risk of TNBC and luminal A-like breast cancer by race and age}

In our stratified analyses examining the association between breastfeeding and TNBC or luminal A-like breast cancer by both race and age, we observed a stronger protective effect of longer duration of breastfeeding against the risk of TNBC among younger parous African-American women $\left(P_{\text {trend }}=0.0004\right.$, Table 5$)$; those who breastfed for 6 months or longer had an 82\% lower risk of TNBC compared to their counterparts who had never breastfed $(\mathrm{OR}=0.18,95 \% \mathrm{CI}=0.07-0.46)$. The other ORs for the association between breastfeeding for 6 months or longer and TNBC or the luminal A-like subtype were $<1$, but their corresponding 95\% CIs included the null value.

\section{Additional results}

The results for ER+/PR+/HER2- breast cancer, the modified definition of the luminal A-like subtype recommended by the $13^{\text {th }}$ St. Gallen International Breast Cancer Conference (2013) Expert Panel, were similar to data presented in the tables for the more commonly used definition (ER+ and/or PR+ plus HER2-) of the luminal A-like breast cancer subtype. Moreover, when we excluded women diagnosed with in situ breast cancer, we found that the results for TNBC were unchanged.

\section{Discussion}

In our pooled analysis of data from three populationbased case-control studies of women aged 20-64 years, we found that longer duration of breastfeeding was associated with decreased risk of both TNBC and the luminal A-like subtype, especially for TNBC among younger (20-44 years) parous African-American women. Younger parous African-American women who breastfed for 6 months or longer had an 82\% lower risk of TNBC than their counterparts who had never breastfed. If this is verified in future research, promotion of breastfeeding, especially in younger African-American women may have a particularly strong impact given the higher risk of TNBC among African-American women [13-16].

Breastfeeding has been proposed to protect against breast cancer through hormonal mechanisms that include postponing the resumption of ovulatory menstrual cycles after a pregnancy [47], reducing estrogen levels in the breast [48], and having fully differentiated breast tissue that is less susceptible to the hormone milieu [49]. It has also been proposed that breastfeeding has a direct mechanical effect, by which carcinogenic agents are excreted from the breast ductal tissue [50]. Moreover, as the amount of involution of terminal duct lobular units has been inversely associated with risk of breast cancer [51], it has been hypothesized that long-term breastfeeding could promote such involution, resulting in decreased risk of breast cancer, and particularly basal-like breast cancers $[52,53]$. The basal-like subtype is defined according to cDNA microarray technology [54]. Because cDNA microarray technology is not yet available clinically, TNBC has become a commonly used proxy for the basal-like subtype in clinical and epidemiologic studies, despite the fact that TNBC and the basal-like subtype are discordant in $20-30 \%$ of cases $[17,55]$.

Our finding of a protective effect of a longer duration of breastfeeding against the risk of TNBC agrees with results from six previous case-control studies [6, 22, 23, $25,27,32]$, a pooled analysis of two case-control studies [8], and one prospective study [21]. Moreover, three case-control studies [15, 26, 28] and the African-American Breast Cancer Epidemiology and Risk (AMBER) Consortium [31] report a non-statistically significant protective effect of breastfeeding on TNBC (risk estimates for the highest category of breastfeeding versus never breastfeeding or lowest category $=0.70-0.91$ ). No inverse association was observed in one case-control study [24] and one prospective study [30]. A meta-analysis published in 2015 [56] concluded that both case-control studies and cohort studies support the evidence that ever breastfeeding is associated with decreased risk of ER-/PR- breast cancer and of TNBC. On average, ever breastfeeding was associated with a $10 \%$ decrease in the risk of ER-/PR- breast cancer and up to a $20 \%$ reduction in the risk of TNBC. A more recent 
Table 4 Multivariable adjusted odds ratio (OR) and 95\% confidence interval (Cl) for ER/PR/HER2-defined subtypes of breast cancer associated with reproductive factors by age

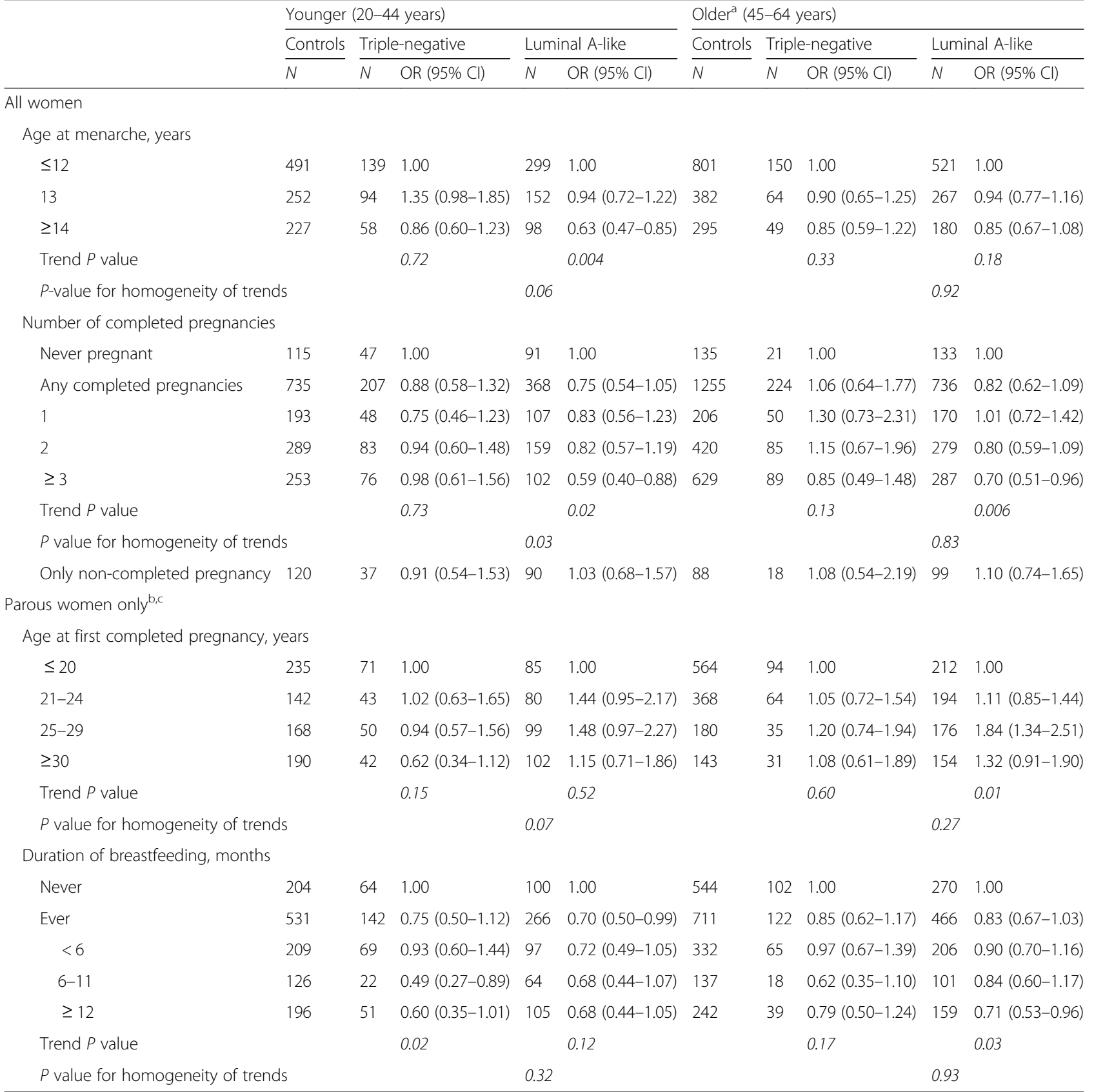

Triple-negative $=$ estrogen receptor (ER)-/progesterone receptor (PR)-/human epidermal growth factor receptor-2 (HER2)-, Luminal A-like $=E R+$ and/or PR+ plus HER2. Models in multivariate analysis included sub-study (the Women's CARE Study or the Women's BCIS Study, the Women's LIFE Study), study site (Los Angeles, Detroit), race (white, Africa-American), reference age (in 5-year age categories), education ( $\leq$ high school, technical school or some college, college graduate), first-degree breast cancer family history (no, yes), body mass index $\left(<25,25-29, \geq 30 \mathrm{~kg} / \mathrm{m}^{2}\right)$, lifetime recreational physical activity (inactive, $\leq 2.2,2.3-6.6,6.7-15.1$, $\geq 15.2$ annual metabolic energy equivalents, hour/week), alcohol intake (never, former, current), cigarette smoking status (never, former, current), age at menarche $(\leq 12,13, \geq 14$ years), number of completed pregnancies (never pregnant, $1,2, \geq 3$, only non-completed pregnancy), oral contraceptive use (never, $<1,1-4,5-9$, $\geq 10$ years). ${ }^{a}$ Additionally adjusted for a variable combining menopausal status and hormone therapy use (premenopausal; postmenopausal: never used hormone therapy, ever used hormone therapy; unknown menopausal status). ${ }^{\mathrm{b}}$ Models additionally included age at first completed pregnancy ( $\leq 20,21-24,25-29, \geq 30$ years) and duration of breastfeeding (never, $<6,6-11, \geq 12$ months). 'Additionally three younger case participants who had missing information on breastfeeding were excluded

meta-analysis published in 2016 [57] showed that ever breastfeeding was associated with a $21 \%$ decrease in the risk of $\mathrm{TNBC}$ (summary $\mathrm{OR}=0.79,95 \% \mathrm{CI}=0.66-0.94$ ).
However, neither of these meta-analyses provided data on the association between breastfeeding duration and risk of TNBC. 
Table 5 Multivariable adjusted odds ratio (OR) and 95\% confidence interval (Cl) for ER/PR/HER2-defined subtypes of breast cancer associated with duration of breastfeeding among parous women by race and age

\begin{tabular}{|c|c|c|c|c|c|c|c|c|c|c|}
\hline & \multicolumn{5}{|c|}{ White women } & \multicolumn{5}{|c|}{ African-American women } \\
\hline & \multirow{2}{*}{$\frac{\overline{\text { Controls }}}{N}$} & \multicolumn{2}{|c|}{ Triple-negative } & \multicolumn{2}{|c|}{ Luminal A-like } & \multirow{2}{*}{$\frac{\text { Controls }}{N}$} & \multicolumn{2}{|c|}{ Triple-negative } & \multicolumn{2}{|c|}{ Luminal A-like } \\
\hline & & N & OR $(95 \% \mathrm{Cl})$ & N & OR $(95 \% \mathrm{Cl})$ & & N & OR $(95 \% \mathrm{Cl})$ & $N$ & OR $(95 \% \mathrm{Cl})$ \\
\hline \multicolumn{11}{|c|}{ Younger (20-44 years) ${ }^{a}$} \\
\hline \multicolumn{11}{|c|}{ Duration of breastfeeding, months } \\
\hline Never & 85 & 27 & 1.00 & 57 & 1.00 & 119 & 37 & 1.00 & 43 & 1.00 \\
\hline Ever & 383 & 105 & $0.85(0.49-1.49)$ & 218 & $0.71(0.46-1.11)$ & 148 & 37 & $0.43(0.22-0.83)$ & 48 & $0.58(0.32-1.06)$ \\
\hline$<6$ & 136 & 43 & $0.94(0.52-1.72)$ & 72 & $0.70(0.43-1.14)$ & 73 & 26 & $0.67(0.33-1.36)$ & 25 & $0.64(0.32-1.26)$ \\
\hline$\geq 6$ & 247 & 62 & $0.76(0.41-1.41)$ & 146 & $0.73(0.45-1.18)$ & 75 & 11 & $0.18(0.07-0.46)$ & 23 & $0.50(0.24-1.06)$ \\
\hline Trend $P$ value & & & 0.34 & & 0.28 & & & 0.0004 & & 0.07 \\
\hline$P$ value for hom & ggeneity of & rends & & 0.93 & & & & & 0.09 & \\
\hline \multicolumn{11}{|l|}{ Older (45-64 years) $)^{b}$} \\
\hline \multicolumn{11}{|c|}{ Duration of breastfeeding, months } \\
\hline Never & 283 & 39 & 1.00 & 171 & 1.00 & 261 & 63 & 1.00 & 96 & 1.00 \\
\hline Ever & 462 & 74 & $1.06(0.65-1.72)$ & 374 & $0.83(0.63-1.10)$ & 249 & 48 & $0.74(0.47-1.17)$ & 92 & $0.90(0.62-1.30)$ \\
\hline$<6$ & 207 & 41 & $1.30(0.78-2.19)$ & 158 & $0.91(0.67-1.25)$ & 125 & 24 & $0.69(0.39-1.21)$ & 48 & $0.94(0.60-1.46)$ \\
\hline$\geq 6$ & 255 & 33 & $0.75(0.41-1.38)$ & 216 & $0.73(0.53-1.02)$ & 124 & 24 & $0.81(0.46-1.43)$ & 44 & $0.85(0.54-1.35)$ \\
\hline Trend $P$ value & & & 0.41 & & 0.07 & & & 0.35 & & 0.49 \\
\hline \multicolumn{4}{|c|}{$P$ value for homogeneity of trends } & \multicolumn{2}{|l|}{0.85} & & & & \multicolumn{2}{|l|}{0.72} \\
\hline
\end{tabular}

Triple negative $=$ estrogen receptor $(E R)-/$ progesterone receptor $(\mathrm{PR})-/$ human epidermal growth factor receptor-2 $(\mathrm{HER} 2)-$, Luminal A-like $=\mathrm{ER}+$ and/or PR+ plus HER2. Models in multivariate analysis included sub-study (the Women's CARE Study or Women's BCIS Study, Women's LIFE Study), study site (Los Angeles, Detroit), reference age (in 5-year age categories), education (< high school, technical school or some college, college graduate), first-degree breast cancer family history (no, yes), body mass index $\left(<25,25-29, \geq 30 \mathrm{~kg} / \mathrm{m}^{2}\right)$, lifetime recreational physical activity (inactive, $\leq 2.2,2.3-6.6,6.7-15.1, \geq 15.2$ annual metabolic energy equivalents, hour/week), alcohol intake (never, former, current), cigarette smoking status (never, former, current), age at menarche ( $\leq 12,13, \geq 14$ years), number of completed pregnancies $(1,2, \geq 3)$, oral contraceptive use (never, $<1,1-4,5-9, \geq 10$ years) and age at first completed pregnancy $\left(\leq 20,21-24,25-29, \geq 30\right.$ years). ${ }^{a}$ Additionally three white younger case participants who had missing information on breastfeeding were excluded. ${ }^{\mathrm{b}}$ Additionally adjusted for a variable combining menopausal status and hormone therapy use (premenopausal; postmenopausal: never used hormone therapy, ever used hormone therapy; unknown menopausal status)

Longer duration of breastfeeding was also associated with decreased risk of the luminal A-like subtype in our pooled analysis. Among previous studies that reported results on the association between breastfeeding and the luminal A-like subtype, breastfeeding was associated with decreased risk of the luminal A-like subtype in three case-control studies $[6,15,22]$, but was not associated with risk of this subtype in three other studies [25, $27,30]$. The meta-analyses published in 2015 [56] and in 2016 [57] did not provide summary results specifically for the luminal A-like subtype. However, the earlier publication [56] provided summary results for the ER+/PR+ subtype and concluded that the evidence for an inverse association between ever breastfeeding and ER+/PR+ breast cancer was observed in case-control studies (summary $\mathrm{OR}=0.86,95 \% \mathrm{CI}=0.79-0.92$ ), but not in cohort studies (summary $\mathrm{RR}=1.00,95 \% \mathrm{CI}=0.90-1.10$ ); the later one [57] provided results for the luminal subtype (ER+ and/or PR+) and showed that ever breastfeeding was associated with a $23 \%$ decrease in risk of the luminal subtype. In summary, the evidence for a protective effect of breastfeeding against the risk of luminal A-like cancer is not as strong as that for TNBC.

It has been well-documented that estrogen and progesterone play important roles in breast tumorigenesis [58-60], and their effects on breast cells are mediated by their respective receptors, the ER and the PR [61-64]. Furthermore, gene expression studies using cDNA microarray technology show that the luminal-A subtype is associated with ER signaling, whereas TNBC is characterized by a basal-like molecular profile, typically expressing genes involved in cell proliferation and differentiation $[54,65]$. In our pooled analysis, the fact that early age at menarche, nulliparity, and late age at first completed pregnancy were all associated with increased risk of luminal A-like breast cancer, but not with TNBC, provides additional evidence that these three reproductive factors affect breast cancer risk predominantly through hormonal mechanisms.

Previous epidemiologic data on the impact of these three factors on the risk of luminal A-like cancer and TNBC are inconsistent, particularly for TNBC. Early age 
at menarche was not associated with risk of TNBC in three case-control studies [22, 23, 27], three prospective studies [20, 21, 30], and one pooled analysis of 34 studies [9]; however, it was a risk factor for TNBC in several other studies [10, 15, 24-26, 29]. Some studies found no association between nulliparity and risk of TNBC $[6,9$, $10,26,27,30,57]$, whereas another reported an increased risk of TNBC associated with nulliparity [23]. Others showed a reduced risk of TNBC with nulliparity $[20,25,28,31,32]$. Some studies found no association of risk of TNBC with late age at first full-term pregnancy $[6,10,20]$ or first birth $[21,26,27,29,30,57]$; one study showed an increased risk of TNBC associated with late age at first birth [24] whereas others showed a reduced risk of TNBC associated with increasing age at first birth $[9,25]$. Our findings are consistent with the majority of previous analyses of early age at menarche $[9,20-23,27,30]$, nulliparity $[6,9,10,26,27,30$, 57], and late age at first full-term pregnancy [6, 10, 20] or first birth [21, 26, 27, 29, 30, 57], showing that these three reproductive factors were not associated with the risk of TNBC.

African-American women are more likely than white women to be diagnosed with TNBC, especially at a young age (<45 years) [13-16]. In the high risk group, we observed an inverse association between breastfeeding and risk of TNBC, suggesting that the protective effect of breastfeeding against risk of TNBC is modified by age and race. To our knowledge, no data have previously been published on effect modification by age for the association between breastfeeding and risk of TNBC. The observed reductions in risk of breast cancer overall in many previously published studies have been stronger for or restricted to younger or premenopausal women [66-71]; however, in some studies, this reduction in risk of breast cancer risk was observed among postmenopausal women [72-74] or was negligible in both premenopausal and postmenopausal women $[75,76]$. Two studies found that the protective effect of breastfeeding against breast cancer decreased with the increasing time since last pregnancy $[66,77]$. The reduction in risk of TNBC associated with breastfeeding was stronger for younger than for older African-American women, which was similar to the results for breast cancer overall. Moreover, there are few data on whether race modifies the association between breastfeeding and TNBC. The study of Work et al. provides some evidence of effect modification: multiparous women ( $\geq 3$ live births) who never breastfed were at increased risk of ER-/PR- breast cancer, whereas multiparous women with a history of breastfeeding were at decreased risk of ER-/PR - breast cancer [32]. These associations were more apparent in African-American women than in non-Hispanic white women. Using data from the AMBER Consortium,
Palmer et al. found that breastfeeding ameliorated the increased risk of TNBC associated with multiparity [31].

Our data also provide some evidence that breastfeeding may be important for limiting the increased risk of TNBC among parous African-American women, but not among parous white women (data not shown). The observed racial difference in our results for the inverse association between breastfeeding and risk of TNBC could not be explained by breastfeeding duration; AfricanAmerican controls and case participants with TNBC had a shorter duration of breastfeeding on average than did white controls and case participants with TNBC (mean breastfeeding duration among those who ever had breastfed: 10.8 and 10.2 months for African-American controls and TNBC case participants, respectively; 12.7 and 13.1 months among white controls and TNBC case participants, respectively). The observed difference in breastfeeding results between African-American women and white women could be related to the differences in other characteristics, such as genetic susceptibility, and requires further study.

Strengths of this pooled analysis include its size, especially the large number of case participants with incident TNBC. Furthermore, the data used in this analysis were collected by trained interviewers, who administered standardized, in-person interviews using structured questionnaires, which were nearly identical across three source studies.

Several limitations of the current study must be considered. First, approximately $36 \%$ of our case participants had missing data on at least one of the receptors (ER, PR, or HER2). We compared our measures of reproductive factors in case patients with and without known ER, PR, or HER2. No statistically significant differences were detected for age at menarche, number of completed pregnancies, or duration of breastfeeding, whereas case patients with information on ER/PR/HER2 were 0.9 years older on average at first completed pregnancy than those with missing information on ER, PR, or HER2 (data not shown). The small difference in average age at first completed pregnancy is unlikely to have altered the observed associations differentially by tumor subtypes.

Second, ER/PR/HER2 status in two of our source studies $[6,35]$ was assayed at the same laboratory using the same methods, whereas in the third source study [33] the information on ER/PR/HER2 status was abstracted from medical records collected by the LACSP. Our previous validation study showed that the associations between reproductive factors and risk of the ER/PR subtypes of breast cancer were similar, whether the ER/PR values were from the same centralized laboratory at the USC providing assays for this analysis or from the LACSP [44]. In addition, we repeated our analyses with the two of our source studies with ER/PR/HER2 values from the centralized USC 
laboratory and found that the results were similar (data not shown) to those presented here.

A final limitation is that IHC was used to assess HER2 protein overexpression without validation by fluorescent in situ hybridization (FISH) analysis in the Women's CARE Study and the Women's BCIS Study. Based on previous validation results from the same centralized USC pathology laboratory, $7.4 \%$ of breast tumors with $H E R 2$ gene amplification in FISH analysis were false negative by 10H8-IHC (scored as 0 or $1+$ ) and $9.7 \%$ of breast cancers without HER2 gene amplification in FISH analysis were false positive [42]. These misclassifications could cause bias towards the null for testing heterogeneity across subtypes involving HER2- versus HER2+ tumors, such as TNBC versus HER2-enriched cancer.

\section{Conclusions}

In this pooled analysis, longer duration of breastfeeding was associated with decreased risk of TNBC especially in younger parous African-American women, suggesting a potential role of breastfeeding in prevention of TNBC among these women.

\section{Abbreviations \\ BCIS: breast carcinoma in situ; BMI: body mass index; CARE: Contraceptive and Reproductive Experiences; Cls: confidence intervals; ER: estrogen receptor; FISH: fluorescent in situ hybridization; HER2: human epidermal growth factor receptor-2; IHC: immunohistochemistry; LA: Los Angeles; LACSP: Los Angeles Cancer Surveillance Program; LCIS: lobular carcinoma in situ; LIFE: Learning the Influence of Family and Environment; MET: metabolic energy equivalent; NICHD: National Institute of Child Health and Human Development; ORs: odds ratios; PR: progesterone receptor; RR: relative risk; TNBC: triple-negative breast cancer; USC: University of Southern California}

\section{Acknowledgements}

We would like to thank Dr. Karen Petrosyan, Armine Arakelyan, Hasmik Toumaian, and Judith Udove for technical assistance in the performance of the immunohistochemical assays for the Women's CARE Study and the Women's BCIS Study. We would also like to thank collaborators who contributed to the development and conduct of the three source studies but who did not directly contribute to the current study. The findings and conclusions in this report are those of the authors and do not necessarily represent the official position of the Centers for Disease Control and Prevention.

\section{Funding}

This analysis was supported by the National Cancer Institute of the National Institutes of Health under Award Number R03CA188549, National Institute for Child Health and Human Development grant N01-HD-3-3175, and National Cancer Institute grant K05-CA136967. Data collection for the Women's CARE Study was supported by the National Institute of Child Health and Human Development and National Cancer Institute, $\mathrm{NIH}$, through contracts with Emory University (N01-HD-3-3168), Fred Hutchinson Cancer Research Center (N01-HD2-3166), Karmanos Cancer Institute at Wayne State University (N01-HD-3-3174), University of Pennsylvania (N01-HD-3-3276), and University of Southern California (N01-HD-3-3175) and Interagency Agreement with Centers for Disease Control and Prevention (Y01-HD-7022). Biomarker determination and analyses for the Women's CARE Study and the Women's BCIS Study were supported by a contract from the National Institute of Child Health and Human Development (N01-HD-3-3175), a grant from the US Army Medical Research \& Development Command (DAMD17-96-1-6156), and a grant from the Breast Cancer Research Foundation (to MF Press). The Women's LIFE study was supported by grants CA17054 and CA74847 from the National Cancer Institute, National Institutes of Health, 4 PB-0092 from the California Breast Cancer
Research Program of the University of California, and in part through contract no. N01-PC-35139. Collection of cancer incidence data in LA County by University of Southern California was supported by California Department of Health Services as part of statewide cancer reporting program mandated by California Health and Safety Code, Section 103885. Support for use of SEER cancer registries was through contracts N01-CN-65064 (Detroit) and N01-PC67010 (LA).

\section{Availability of data and materials}

The data supporting the conclusions of this report are included within the article.

\section{Authors' contributions}

HM obtained funding to conduct the analyses of TNBC risk factors using data collected previously for Women's CARE Study, the Women's BCIS Study, and the Women's LIFE Study. XX conducted data analyses under HM's supervision. HM interpreted the results and drafted the manuscript. All authors participated in the critical revision of the manuscript and have read and approved the final version. For the three source studies: KEM, PAM DMD, and LB conceived of and designed the Women's CARE Study. KEM, PAM, SGF, JAM, DMD, JSH, and LB supervised or participated in the data collection and assembly of data of the Women's CARE Study. MSS and MFP helped to interpret medical questions during the conduct of the Women's CARE Study. LB conceived of, designed, and supervised data collection and assembly of data for the Women's BCIS Study. MFP and LB conceived of and designed the pathology sub-studies of the Women's CARE Study and the Women's BCIS Study. MFP conducted the assessment of biomarkers for case participants of the Women's CARE Study (restricted to Los Angeles and Detroit) and the Women's BCIS Study. GU conceived of and designed the Women's LIFE Study. GU and LB supervised the data collection activities in the Women's LIFE Study.

\section{Competing interests}

The authors declare that they have no competing interests.

\section{Consent for publication}

Not applicable.

\section{Ethics approval and consent to participate}

All source studies obtained written, informed consent from all participants and approval from their respective Institutional Review Boards (University of Southern California IRB\#: HS-981007, City of Hope IRB\#: 14250).

\section{Author details}

${ }^{1}$ Department of Population Sciences, Beckman Research Institute, 1500 East Duarte Rd. Duarte, City of Hope, CA 91010, USA. ${ }^{2}$ Cancer Registry of Norway, Oslo, Norway. ${ }^{3}$ Department of Nutrition, Institute of Basic Medical Sciences, University of Oslo, Oslo, Norway. ${ }^{4}$ Department of Preventive Medicine, Keck School of Medicine, University of Southern California, Los Angeles, CA 90033, USA. ${ }^{5}$ Section of Environment and Radiation, International Agency for Research on Cancer, Lyon, France. ${ }^{6}$ School of Social Work, University of Southern California, Los Angeles, CA 90033, USA. ${ }^{7}$ Division of Public Health Sciences, Fred Hutchinson Cancer Research Center, Seattle, WA 98109, USA ${ }^{8}$ Division of Reproductive Health, Centers for Disease Control and Prevention, Atlanta, GA 30333, USA. ${ }^{9}$ College of Health and Social Services, New Mexico State University, Las Cruces, NM 88003, USA. ${ }^{10}$ Karmanos Cancer Institute, Department of Oncology, Wayne State University, Detroit, MI 48201, USA.

${ }^{11}$ Pathology, Keck School of Medicine, University of Southern California, Los Angeles, CA 90033, USA.

Received: 27 October 2016 Accepted: 22 December 2016 Published online: 13 January 2017

\section{References}

1. Ferlay J, Parkin DM, Steliarova-Foucher E. Estimates of cancer incidence and mortality in Europe in 2008. Eur J Cancer. 2010;46(4):765-81.

2. Bauer KR, Brown M, Cress RD, Parise CA, Caggiano V. Descriptive analysis of estrogen receptor (ER)-negative, progesterone receptor (PR)-negative, and HER2-negative invasive breast cancer, the so-called triple-negative phenotype: a population-based study from the California cancer Registry. Cancer. 2007;109(9):1721-8. 
3. Carey LA, Dees EC, Sawyer L, Gatti L, Moore DT, Collichio F, Ollila DW, Sartor $\mathrm{Cl}$, Graham ML, Perou CM. The triple negative paradox: primary tumor chemosensitivity of breast cancer subtypes. Clin Cancer Res. 2007;13(8): 2329-34.

4. Dent R, Trudeau M, Pritchard KI, Hanna WM, Kahn HK, Sawka CA, Lickley LA, Rawlinson E, Sun P, Narod SA. Triple-negative breast cancer: clinical features and patterns of recurrence. Clin Cancer Res. 2007;13(15 Pt 1):4429-34.

5. Ma H, Luo J, Press MF, Wang Y, Bernstein L, Ursin G. Is there a difference in the association between percent mammographic density and subtypes of breast cancer? Luminal A and triple-negative breast cancer. Cancer Epidemiol Biomarkers Prev. 2009;18(2):479-85.

6. Ma H, Wang Y, Sullivan-Halley J, Weiss L, Marchbanks PA, Spirtas R, Ursin G, Burkman RT, Simon MS, Malone KE, et al. Use of four biomarkers to evaluate the risk of breast cancer subtypes in the women's contraceptive and reproductive experiences study. Cancer Res. 2010;70(2):575-87.

7. Onitilo AA, Engel JM, Greenlee RT, Mukesh BN. Breast cancer subtypes based on ER/PR and Her2 expression: comparison of clinicopathologic features and survival. Clin Med Res. 2009;7(1-2):4-13.

8. Phipps Al, Malone KE, Porter $\mathrm{PL}$, Daling JR, Li Cl. Reproductive and hormonal risk factors for postmenopausal luminal, HER-2-overexpressing, and triplenegative breast cancer. Cancer. 2008;113(7):1521-6.

9. Yang XR, Chang-Claude J, Goode EL, Couch FJ, Nevanlinna H, Milne RL, Gaudet M, Schmidt MK, Broeks A, Cox A, et al. Associations of breast cancer risk factors with tumor subtypes: a pooled analysis from the Breast Cancer Association Consortium studies. J Natl Cancer Inst. 2011;103(3):250-63.

10. Yang XR, Sherman ME, Rimm DL, Lissowska J, Brinton LA, Peplonska B, Hewitt SM, Anderson WF, Szeszenia-Dabrowska N, Bardin-Mikolajczak A, et al. Differences in risk factors for breast cancer molecular subtypes in a population-based study. Cancer Epidemiol Biomark Prev. 2007;16(3): 439-43.

11. Perou CM. Molecular stratification of triple-negative breast cancers. Oncologist. 2011;16 Suppl 1:61-70.

12. Schneider BP, Winer EP, Foulkes WD, Garber J, Perou CM, Richardson A, Sledge GW, Carey LA. Triple-negative breast cancer: risk factors to potential targets. Clin Cancer Res. 2008;14(24):8010-8.

13. Lund MJ, Trivers KF, Porter PL, Coates RJ, Leyland-Jones B, Brawley OW, Flagg EW, O'Regan RM, Gabram SG, Eley JW. Race and triple negative threats to breast cancer survival: a population-based study in Atlanta, GA. Breast Cancer Res Treat. 2009;113(2):357-70.

14. Kwan ML, Kushi LH, Weltzien E, Maring B, Kutner SE, Fulton RS, Lee MM, Ambrosone CB, Caan BJ. Epidemiology of breast cancer subtypes in two prospective cohort studies of breast cancer survivors. Breast Cancer Res. 2009;11(3):R31.

15. Trivers KF, Lund MJ, Porter PL, Liff JM, Flagg EW, Coates RJ, Eley JW. The epidemiology of triple-negative breast cancer, including race. Cancer Causes Control. 2009;20:1071-82.

16. Amirikia KC, Mills P, Bush J, Newman LA. Higher population-based incidence rates of triple-negative breast cancer among young African-American women: implications for breast cancer screening recommendations. Cancer. 2011;117(12):2747-53.

17. Anders CK, Carey LA. Biology, metastatic patterns, and treatment of patients with triple-negative breast cancer. Clin Breast Cancer. 2009;9 Suppl 2:S73-81.

18. Hudis CA, Gianni L. Triple-negative breast cancer: an unmet medical need. Oncologist. 2011;16 Suppl 1:1-11.

19. Kaplan HG, Malmgren JA. Impact of triple negative phenotype on breast cancer prognosis. Breast J. 2008;14(5):456-63.

20. Phipps Al, Chlebowski RT, Prentice R, McTiernan A, Wactawski-Wende J, Kuller LH, Adams-Campbell LL, Lane D, Stefanick ML, Vitolins M, et al. Reproductive history and oral contraceptive use in relation to risk of triplenegative breast cancer. J Natl Cancer Inst. 2011;103(6):470-7.

21. Tamimi RM, Colditz GA, Hazra A, Baer HJ, Hankinson SE, Rosner B, Marotti J, Connolly JL, Schnitt SJ, Collins LC. Traditional breast cancer risk factors in relation to molecular subtypes of breast cancer. Breast Cancer Res Treat. 2012:131(1):159-67.

22. Xing P, Li J, Jin F. A case-control study of reproductive factors associated with subtypes of breast cancer in Northeast China. Med Oncol. 2010;27(3):926-31.

23. Li Cl, Beaber EF, Tang MT, Porter PL, Daling JR, Malone KE. Reproductive factors and risk of estrogen receptor positive, triple-negative, and HER2-neu overexpressing breast cancer among women 20-44 years of age. Breast Cancer Res Treat. 2013;137(2):579-87.
24. Dolle JM, Daling JR, White E, Brinton LA, Doody DR, Porter PL, Malone KE. Risk factors for triple-negative breast cancer in women under the age of 45 years. Cancer Epidemiol Biomark Prev. 2009;18(4):1157-66.

25. Millikan RC, Newman B, Tse CK, Moorman PG, Conway K, Smith LV, Labbok $\mathrm{MH}$, Geradts J, Bensen JT, Jackson S, et al. Epidemiology of basal-like breast cancer. Breast Cancer Res Treat. 2008;109:123-39.

26. Islam T, Matsuo K, Ito H, Hosono S, Watanabe M, Iwata H, Tajima K, Tanaka $H$. Reproductive and hormonal risk factors for luminal, HER2-overexpressing, and triple-negative breast cancer in Japanese women. Ann Oncol. 2012; 23(9):2435-41.

27. Gaudet MM, Press MF, Haile RW, Lynch CF, Glaser SL, Schildkraut J, Gammon MD, Douglas Thompson W, Bernstein JL. Risk factors by molecular subtypes of breast cancer across a population-based study of women 56 years or younger. Breast Cancer Res Treat. 2011;130(2):587-97.

28. Ambrosone CB, Zirpoli G, Ruszczyk M, Shankar J, Hong CC, Mcllwain D, Roberts M, Yao S, McCann SE, Ciupak G, et al. Parity and breastfeeding among African-American women: differential effects on breast cancer risk by estrogen receptor status in the Women's Circle of Health Study. Cancer Causes Control. 2014;25(2):259-65.

29. Ambrosone CB, Zirpoli G, Hong CC, Yao S, Troester MA, Bandera EV, Schedin $P$, Bethea TN, Borges $V$, Park SY, et al. Important role of menarche in development of estrogen receptor-negative breast cancer in African American women. J Nat Cancer Inst. 2015;107(9). doi:10.1093/jnci/djv172.

30. Horn J, Opdahl S, Engstrom MJ, Romundstad PR, Tretli S, Haugen OA, Bofin AM, Vatten LJ, Asvold BO. Reproductive history and the risk of molecular breast cancer subtypes in a prospective study of Norwegian women. Cancer Causes Control. 2014;25(7):881-9.

31. Palmer JR, Viscidi E, Troester MA, Hong CC, Schedin P, Bethea TN, Bandera EV, Borges V, McKinnon C, Haiman CA, et al. Parity, lactation, and breast cancer subtypes in African American women: results from the AMBER Consortium. J Nat Cancer Inst. 2014;106(10). doi:10.1093/jnci/dju237.

32. Work ME, John EM, Andrulis IL, Knight JA, Liao Y, Mulligan AM, Southey MC, Giles GG, Dite GS, Apicella C, et al. Reproductive risk factors and oestrogen/ progesterone receptor-negative breast cancer in the Breast Cancer Family Registry. Br J Cancer. 2014;110(5):1367-77.

33. Ma H, Bernstein L, Ross RK, Ursin G. Hormone-related risk factors for breast cancer in women under age 50 years by estrogen and progesterone receptor status: results from a case-control and a case-case comparison. Breast Cancer Res. 2006;8(4):R39.

34. Lee E, McKean-Cowdin E, Ma H, Spicer D, Van Den Berg D, Bernstein L, Ursin G. Characteristics of triple-negative breast cancer in patients with a BRCA1 mutation, results from a population-based study of women under age 50 (what characterizes young women who develop triple-negative cancer?). J Clin Oncol. 2011;29(33):4373-80.

35. Patel AV, Press MF, Meeske K, Calle EE, Bernstein L. Lifetime recreational exercise activity and risk of breast carcinoma in situ. Cancer. 2003;98(10): 2161-9.

36. Marchbanks PA, McDonald JA, Wilson HG, Burnett NM, Daling JR, Bernstein L, Malone KE, Strom BL, Norman SA, Weiss LK, et al. The NICHD Women's Contraceptive and Reproductive Experiences Study: methods and operational results. Ann Epidemiol. 2002;12(4):213-21.

37. Hanby AM, Hughes TA. In situ and invasive lobular neoplasia of the breast. Histopathology. 2008:52(1):58-66.

38. Lee E, McKean-Cowdin R, Ma H, Chen Z, Van Den Berg D, Henderson BE, Bernstein L, Ursin G. Evaluation of unclassified variants in the breast cancer susceptibility genes BRCA1 and BRCA2 using five methods: results from a population-based study of young breast cancer patients. Breast Cancer Res. 2008;10(1):R19.

39. Press M, Spaulding B, Groshen S, Kaminsky D, Hagerty M, Sherman L, Christensen K, Edwards DP. Comparison of different antibodies for detection of progesterone receptor in breast cancer. Steroids. 2002;67(9):799-813.

40. Finn RS, Press MF, Dering J, Arbushites M, Koehler M, Oliva C, Williams LS, Di Leo $A$. Estrogen receptor, progesterone receptor, human epidermal growth factor receptor 2 (HER2), and epidermal growth factor receptor expression and benefit from lapatinib in a randomized trial of paclitaxel with lapatinib or placebo as first-line treatment in HER2-negative or unknown metastatic breast cancer. J Clin Oncol. 2009;27(24):3908-15.

41. Hammond ME, Hayes DF, Dowsett M, Allred DC, Hagerty KL, Badve S, Fitzgibbons PL, Francis G, Goldstein NS, Hayes M, et al. American Society of Clinical Oncology/College of American Pathologists quideline recommendations for immunohistochemical testing of estrogen and 
progesterone receptors in breast cancer (unabridged version). Arch Pathol Lab Med. 2010;134(7):e48-72.

42. Press MF, Sauter G, Bernstein L, Villalobos IE, Mirlacher M, Zhou J-Y, Wardeh R, Li Y-T, Guzman R, Ma Y, et al. Diagnostic evaluation of HER-2 as a molecular target: an assessment of accuracy and reproducibility of laboratory testing in large, prospective, randomized clinical trials. Clin Cancer Res. 2005;11(18):6598-607.

43. Press MF, Slamon DJ, Flom KJ, Park J, Zhou J-Y, Bernstein L. Evaluation of HER-2/neu Gene amplification and overexpression: comparison of frequently used assay methods in a molecularly characterized cohort of breast cancer specimens. J Clin Oncol. 2002;20(14):3095-105.

44. Ma H, Wang Y, Sullivan-Halley J, Weiss L, Burkman RT, Simon MS, Malone KE, Strom BL, Ursin G, Marchbanks PA, et al. Breast cancer receptor status: do results from a centralized pathology laboratory agree with SEER registry reports? Cancer Epidemiol Biomarkers Prev. 2009;18(8):2214-20.

45. Hosmer DW, Lemeshow S. Applied logistic regression. New York: A WileyInterscience Publication; 2000.

46. Goldhirsch A, Winer EP, Coates AS, Gelber RD, Piccart-Gebhart M, Thurlimann B, Senn HJ, Panel M. Personalizing the treatment of women with early breast cancer: highlights of the St Gallen International Expert Consensus on the Primary Therapy of Early Breast Cancer 2013. Ann Oncol. 2013;24(9):2206-23.

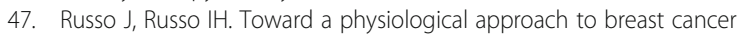
prevention. Cancer Epidemiol Biomark Prev. 1994;3(4):353-64.

48. Petrakis NL, Wrensch MR, Ernster VL, Miike R, Murai J, Simberg N, Siiteri PK. Influence of pregnancy and lactation on serum and breast fluid estrogen levels: implications for breast cancer risk. Int J Cancer. 1987;40(5):587-91.

49. Russo J, Hu YF, Yang X, Russo $\mid H$. Developmental, cellular, and molecular basis of human breast cancer. J Natl Cancer Inst Monogr. 2000;27:17-37.

50. Murrell TG. Epidemiological and biochemical support for a theory on the cause and prevention of breast cancer. Med Hypotheses. 1991;36(4):389-96.

51. Milanese TR, Hartmann LC, Sellers TA, Frost MH, Vierkant RA, Maloney SD, Pankratz VS, Degnim AC, Vachon CM, Reynolds CA, et al. Age-related lobular involution and risk of breast cancer. J Natl Cancer Inst. 2006;98(22):1600-7.

52. Faupel-Badger JM, Arcaro KF, Balkam JJ, Eliassen AH, Hassiotou F, Lebrilla CB, Michels KB, Palmer JR, Schedin P, Stuebe AM, et al. Postpartum remodeling, lactation, and breast cancer risk: summary of a National Cancer Institute-sponsored workshop. J Natl Cancer Inst. 2013;105(3):166-74.

53. Yang XR, Figueroa JD, Falk RT, Zhang H, Pfeiffer RM, Hewitt SM, Lissowska J, Peplonska B, Brinton L, Garcia-Closas M, et al. Analysis of terminal duct lobular unit involution in luminal $A$ and basal breast cancers. Breast Cancer Res. 2012;14(2):R64.

54. Sorlie T, Wang Y, Xiao C, Johnsen H, Naume B, Samaha RR, Borresen-Dale AL, Sorlie T, Wang Y, Xiao C, et al. Distinct molecular mechanisms underlying clinically relevant subtypes of breast cancer: gene expression analyses across three different platforms. BMC Genomics. 2006;7:127.

55. Kreike B, van Kouwenhove M, Horlings $H$, Weigelt B, Peterse H, Bartelink H, van de Vijver MJ. Gene expression profiling and histopathological characterization of triple-negative/basal-like breast carcinomas. Breast Cancer Res. 2007;9(5):R65.

56. Islami F, Liu Y, Jemal A, Zhou J, Weiderpass E, Colditz G, Boffetta P, Weiss M. Breastfeeding and breast cancer risk by receptor status-a systematic review and meta-analysis. Ann Oncol. 2015;26(12):2399-407.

57. Lambertini M, Santoro L, Del Mastro L, Nguyen B, Livraghi L, Ugolini D, Peccatori FA, Azim Jr HA. Reproductive behaviors and risk of developing breast cancer according to tumor subtype: A systematic review and meta-analysis of epidemiological studies. Cancer Treat Rev. 2016;49:65-76.

58. Henderson BE, Ross RK, Pike MC, Casagrande JT. Endogenous hormones as a major factor in human cancer. Cancer Res. 1982;42(8):3232-9.

59. Key TJPM. The role of oestrogens and progestagens in the epidemiology and prevention of breast cancer. Eur J cancer Clin Oncol. 1988;24:29-43.

60. Bernstein L, Ross RK. Endogenous hormones and breast cancer risk. Epidemiol Rev. 1993;15(1):48-65.

61. Anderson $\mathrm{E}$. The role of oestrogen and progesterone receptors in human mammary development and tumorigenesis. Breast Cancer Res. 2002;4(5): 197-201.

62. Dickson RB, Stancel GM. Estrogen receptor-mediated processes in normal and cancer cells. J Natl Cancer Inst Monogr. 2000;27:135-45.

63. Evans RM. The steroid and thyroid hormone receptor superfamily. Science. 1988;240(4854):889-95.

64. Gorski J, Gannon F. Current models of steroid hormone action: a critique. Annu Rev Physiol. 1976;38:425-50.
65. Sorlie T, Tibshirani R, Parker J, Hastie T, Marron JS, Nobel A, Deng S, Johnsen H, Pesich R, Geisler S, et al. Repeated observation of breast tumor subtypes in independent gene expression data sets. Proc Natl Acad Sci U S A. 2003; 100(14):8418-23.

66. Enger SM, Ross RK, Henderson B, Bernstein L. Breastfeeding history, pregnancy experience and risk of breast cancer. Br J Cancer. 1997;76(1):118-23.

67. Kelsey JL, Gammon MD, John EM. Reproductive factors and breast cancer. Epidemiol Rev. 1993;15(1):36-47.

68. McCredie M, Paul C, Skegg DC, Williams S. Reproductive factors and breast cancer in New Zealand. Int J Cancer. 1998;76(2):182-8.

69. Newcomb PA, Storer BE, Longnecker MP, Mittendorf R, Greenberg ER, Clapp RW, Burke KP, Willett WC, MacMahon B. Lactation and a reduced risk of premenopausal breast cancer. N Engl J Med. 1994;330(2):81-7.

70. Tryggvadottir L, Tulinius H, Eyfjord JE, Sigurvinsson T. Breastfeeding and reduced risk of breast cancer in an Icelandic cohort study. Am J Epidemiol. 2001;154(1):37-42.

71. Zheng T, Duan L, Liu Y, Zhang B, Wang Y, Chen Y, Zhang Y, Owens PH. Lactation reduces breast cancer risk in Shandong Province. China Am J Epidemiol. 2000;152(12):1129-35.

72. Enger SM, Ross RK, Paganini-Hill A, Bernstein L. Breastfeeding experience and breast cancer risk among postmenopausal women. Cancer Epidemiol Biomark Prev. 1998;7(5):365-9.

73. Newcomb PA, Egan KM, Titus-Ernstoff L, Trentham-Dietz A, Greenberg ER, Baron JA, Willett WC, Stampfer MJ. Lactation in relation to postmenopausal breast cancer. Am J Epidemiol. 1999;150(2):174-82.

74. Romieu I, Hernandez-Avila M, Lazcano E, Lopez L, Romero-Jaime R. Breast cancer and lactation history in Mexican women. Am J Epidemiol. 1996; 143(6):543-52.

75. Michels KB, Trichopoulos D, Rosner BA, Hunter DJ, Colditz GA, Hankinson SE, Speizer FE, Willett WC. Being breastfed in infancy and breast cancer incidence in adult life: results from the two nurses' health studies. Am J Epidemiol. 2001;153(3):275-83.

76. Negri E, Braga C, La Vecchia C, Levi F, Talamini R, Franceschi S. Lactation and the risk of breast cancer in an Italian population. Int J Cancer. 1996; 67(2):161-4.

77. Ursin G, Bernstein L, Wang Y, Lord SJ, Deapen D, Liff JM, Norman SA, Weiss LK, Daling JR, Marchbanks PA, et al. Reproductive factors and risk of breast carcinoma in a study of white and African-American women. Cancer. 2004; 101(2):353-62.

\section{Submit your next manuscript to BioMed Central and we will help you at every step:}

- We accept pre-submission inquiries

- Our selector tool helps you to find the most relevant journal

- We provide round the clock customer support

- Convenient online submission

- Thorough peer review

- Inclusion in PubMed and all major indexing services

- Maximum visibility for your research

Submit your manuscript at www.biomedcentral.com/submit 